ISSN 0103-8478

\title{
Construção e uso de indicadores para avaliação do manejo da ordenha: uma proposta metodológica participativa
}

\author{
Construction and use of indicators to assess milking \\ management: a participatory methodology proposal
}

\author{
Alexandre Prestes de Souza ${ }^{\mathrm{I}}$ Luciana Aparecida Honorato ${ }^{\mathrm{II}}$ \\ Cíntia Uller Gómez ${ }^{\mathrm{III}}$ Clarissa Silva Cardoso ${ }^{\mathrm{I}}$ Maria José Hötzel $^{{ }^{*}}$
}

\section{RESUMO}

O objetivo deste trabalho foi adaptar e testar uma metodologia participativa para promover e avaliar as mudanças de percepção e de atitude dos agricultores com relação às práticas de manejo sanitário da ordenha, através da construção e uso de indicadores que permitissem aos agricultores um processo de ação-avaliação constante. Foi realizado um estudo de caso em quatro Unidades de Produção Familiar (UPF), no município de Guaraciaba (SC), envolvidas na atividade leiteira. Após a caracterização das UPF e diagnóstico sanitário do rebanho, foi feita a construção participativa de indicadores de manejo sanitário de ordenha, a qual foi utilizada pelos agricultores ao longo de três meses para avaliação de suas práticas de manejo. Ao final desse período, foram realizadas entrevistas com as famílias participantes para apreender a sua percepção a respeito da metodologia empregada. Os agricultores avaliaram positivamente o uso da metodologia, destacando a melhoria de vários indicadores, devido às mudanças de atitudes. Destacaram também que a eficiência da metodologia se deve ao fato de ela proporcionar uma reflexão sobre aspectos reais da vida dos agricultores. Assim, a proposta metodológica participativa utilizada neste trabalho, dentro de uma perspectiva emancipadora, mostrou-se uma importante ferramenta de avaliação de sistemas, coerente com as premissas da Política Nacional de Assistência Técnica e Extensão Rural - PNATER.

Palavras-chave: metodologia participativa, MESMIS, manejo da ordenha, extensão rural, agricultura familiar.

\section{ABSTRACT}

The aim of this study was to adapt and test a participatory methodology to promote and assess changes in perception and attitude of farmers regarding management sanitary milking practices, through the construction and use of indicators that may allow farmers a constant process of self-evaluation. We conducted a case study in four Family Farms (UPF), in the municipality of Guaraciaba (SC) involved in the dairy business. First a characterization of the UPF and diagnosis of herd health were carried out. The second step was the construction of participatory indicators for sanitary milking management, which were used by farmers over three months for evaluation of their management practices. After this period participating families were interviewed with to grasp their perceptions towards the methodology employed. Farmers gave a positive assessment of the use of the methodology, highlighting the improvement of various indicators due to changes in attitudes promoted by the use of the methodology. They also highlighted that the efficiency of the method is due to the fact that it can provide a reflection on real aspects of the farmers' life. Thus, the participatory methodology used in this study within an emancipatory perspective, proved to be an important tool for evaluating systems, consistent with the assumptions referred in the National Technical Assistance and Rural Extension - PNATER.

Key words: participatory methodology, MESMIS, milking management, agricultural extension, family farming.

\section{INTRODUÇÃO}

Embora a atividade leiteira seja relevante para a economia brasileira, o leite produzido e consumido no país nem sempre apresenta a qualidade desejada e muitos são os esforços de empresas públicas e privadas para desenvolver metodologias capazes de auxiliar na melhoria da qualidade da matéria

\footnotetext{
ILaboratório de Etologia Aplicada (LETA), Departamento de Zootecnia e Desenvolvimento Rural (DZDR), Universidade Federal de Santa Catarina (UFSC), Rodovia Admar Gonzaga, 1346, Itacorubi, 88034-001, Florianópolis, SC, Brasil. E-mail: mjhotzel@cca.ufsc.br.*Autor para correspondência.

IIFundação Estadual de Pesquisa Agropecuária (FEPAGRO), Instituto de Pesquisas Veterinária Desidério Finamor (IPVDF), Eldorado do Sul, RS, Brasil.

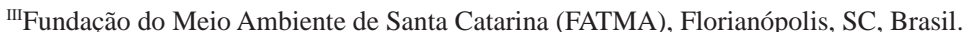


prima. Tais metodologias envolvem, geralmente, capacitações e treinamentos para difundir melhores práticas de manejo dos animais e do ambiente de criação. No entanto, percebe-se uma dificuldade de aceitação e de aplicação prática das orientações por parte dos agricultores, exemplo evidenciado no baixo uso de várias práticas preventivas no manejo da ordenha entre 120 agricultores familiares de Santa Catarina (COSTA et al., 2013). TAVOLARO et al. (2006) investigaram o conhecimento de ordenhadores de cabras sobre a higiene nas operações de ordenha, antes e após uma capacitação, e não identificaram diferenças entre esses dois momentos, o que indica uma clara deficiência no processo de apropriação do conteúdo. ENRÍQUEZ et al. (2007), por sua vez, concluíram que, mesmo após a realização de cursos, a adoção de práticas relacionadas à prevenção de doenças nos animais, ambiente e manejo dos rebanhos leiteiros bovinos foi baixa.

Os motivos que levam à baixa aceitação ou a não aplicação pelos produtores das mudanças propostas para melhoria de suas práticas de manejo ainda são pouco compreendidos. ULLER-GÓMEZ \& GARTNER(2008) argumentam que a apropriação de um conhecimento novo envolve rupturas com os conhecimentos e práticas com base nos quais o agricultor construiu a sua visão da realidade. Essa forma de atuação está alinhada com a proposta de educação popular iniciada na América Latina nos anos 1970 com a proposta pedagógica de Paulo Freire. Conforme CARRILLO (2010), durante quatro décadas, centenas de grupos com projetos e práticas diversos têm se abrigado sob o termo "educação popular”, com a intenção comum de permitir que diversos segmentos das classes populares constituamse como sujeitos e protagonistas de profunda mudança social. As novas propostas de extensão rural, entre elas a Política Nacional de Assistência Técnica e Extensão Rural - PNATER (BRASIL, 2004) têm premissas que vão ao encontro da educação popular, destacandose a promoção da avaliação crítica da percepção dos agricultores sobre a sua própria atividade, utilizando metodologias participativas que valorizem as suas ações.

Nesse sentido, a presente proposta utiliza o "Marco para la Evaluación de Sistemas de Manejo de Recursos Naturales Incorporando Indicadores de Sustentabilidad” (MESMIS), uma metodologia de ação-avaliação usada para avaliar a sustentabilidade de sistemas, que já foi validada em várias regiões do mundo e em diferentes áreas das ciências agrárias (ASTIER et al., 2012). O uso de indicadores compõe uma ferramenta metodológica capaz de mobilizar a população rural para a resolução de seus problemas (CASADO \& MIELGO, 2007). O objetivo do presente trabalho foi adaptar a metodologia MESMIS à avaliação do manejo sanitário da ordenha e verificar se ela é capaz de promover mudanças de atitude e de percepção dos agricultores com relação às mesmas práticas. Especificamente, verificou-se o grau de adoção das práticas de manejo recomendadas e a percepção dos agricultores sobre a metodologia.

\section{MATERIAL E MÉTODOS}

Local do estudo e seleção dos participantes

Um estudo de caso foi realizado entre os meses de novembro de 2011 e outubro de 2012, envolvendo quatro unidades de produção familiar (UPF) inseridas na atividade leiteira, no município de Guaraciaba, extremo oeste do Estado de Santa Catarina (entre $26^{\circ} 36^{\prime} \mathrm{S} 53^{\circ} 34^{\prime} \mathrm{W}$ ). O município conta com uma população de 10.498 habitantes, sendo destes 53\% na área rural. Possui um rebanho bovino de 31.334 cabeças, distribuídas em 1.442 estabelecimentos agropecuários, cuja área média é de 25,4 ha e dos quais $77,2 \%$ trabalham na atividade leiteira. O volume de leite produzido por ano é de 27.852 mil litros e 9.605 vacas ordenhadas, segundo o IBGE (2010). As UPFs foram selecionadas a partir de manifestação voluntária dos agricultores em uma reunião, na qual foi apresentada a ideia do projeto a pessoas que integram a Associação Central das Microbacias Hidrográficas de Guaraciaba, entidade jurídica sem fins lucrativos que tem 1.200 famílias de agricultores associados. Participaram das atividades de pesquisa 11 pessoas das quatro UPF.

O método de estudo de caso nos moldes propostos vem ao encontro das premissas da Política Nacional de Assistência Técnica e Extensão Rural PNATER, que determina que as assistências técnicas e extensão rural financiadas com recursos públicos estejam pautadas "pela intercomplementariedade e respeito mútuo, sobretudo no que se refere ao conhecimento dos agricultores” (BRASIL, 2004). Mussoi (2006), entre outros autores, acreditam que os novos pressupostos para a prática de assistência técnica e extensão rural significam reais possibilidades de mudança e construção de autonomia para os agricultores.

A pouca eficácia das metodologias utilizadas pela extensão rural para capacitar agricultores familiares em boas práticas no manejo da ordenha exige uma mudança de abordagem. Um método que garanta a participação e o envolvimento das famílias é condição sine qua non para a avaliação da percepção e das mudanças de atitude desses agricultores com relação a essas práticas. Nesse contexto, este estudo constituiu-se de uma 
pesquisa-ação, primando pela análise qualitativa do processo, necessária para tomar em conta os saberes dos agricultores e problematizá-los ao longo do monitoramento, para que, posteriormente, seja possível aplicar o método a um número maior de famílias. Além disso, devido ao ineditismo da aplicação do MESMIS em manejo de ordenha, optouse por utilizar um número reduzido de famílias para um melhor acompanhamento e avaliação.

\section{Caracterização das UPF estudadas}

Foi feita uma entrevista semiestruturada em cada UPF, contemplando aspectos produtivos, sociais, ambientais e do sistema de manejo de ordenha, e complementada pelo acompanhamento da ordenha. Nesta, foi feito o diagnóstico de mastite, através do California Mastitis Test (CMT), para registro da porcentagem de vacas afetadas, e avaliado o escore de condição corporal (ECC), conforme descrito por COSTA et al. (2013). A presença de ectoparasitas foi avaliada de forma visual, considerando-se a ausência ou presença, expressa em percentual do rebanho afetado.

Construção participativa de indicadores de manejo sanitário de ordenha

A construção de indicadores de manejo sanitário de ordenha foi feita em uma reunião com membros das quatro UPF. Para identificar a percepção dos agricultores em relação ao tema proposto, fez-se a seguinte pergunta: “O que, na opinião de vocês, é mais importante no manejo de ordenha para se obter um leite de qualidade?". Os agricultores responderam por escrito e as respostas foram compiladas no quadro. As respostas constituíram os “descritores" - aspectos percebidos por eles como necessários para a sustentação e permanência do sistema; em discussão com os técnicos, estes foram agrupados em indicadores, para mensuração do sistema avaliado.

Os seguintes indicadores passaram a constituir a base para avaliação do sistema: saúde do rebanho, higiene de equipamentos, ectoparasitas, controle da mastite, higiene dos tetos, atendimento veterinário, alimentação, bemestar animal, higiene do ordenhador, refrigeração do leite, manutenção do equipamento, higiene do ambiente, orientação técnica, aplicação de medicamentos, Contagem Padrão em Placas (CPP) e Contagem de Células Somáticas (CCS).

Capacitação em boas práticas no manejo sanitário de ordenha e monitoramento

A etapa seguinte foi uma capacitação focada nas boas práticas no manejo sanitário da ordenha, tendo como roteiro os indicadores e uma explanação sobre a IN 62 (BRASIL, 2011). O monitoramento dos indicadores nas UPF e avaliação da qualidade microbiológica do leite foram realizados pelo período de três meses consecutivos. A primeira avaliação foi feita antes da capacitação e as outras duas após a capacitação.

Para a avaliação dos indicadores, o pesquisador descrevia os parâmetros para cada indicador, solicitando aos agricultores que pensassem nas suas práticas relacionadas ao manejo sanitário de ordenha e as avaliassem, atribuindo uma nota entre 1 a 10 (sendo 1 o valor menos desejável e 10 o valor mais desejado). Nos estabelecimentos onde mais de uma pessoa era responsável pela ordenha, considerou-se a nota média desses. Todos os indicadores foram avaliados pelos próprios agricultores, com exceção da CCS e CPP, que foram avaliados através dos resultados das análises laboratoriais fornecidas pela empresa que recolhe o leite nas propriedades. Para subsidiar a autoavaliação, também foram fornecidos pelo pesquisador dados sobre CMT, ECC e presença de ectoparasitas, coletados durante o acompanhamento da ordenha.

Após a avaliação dos indicadores em cada unidade produtiva, os dados foram representados em um gráfico do tipo ameba, adaptado de ALTIERI \& NICHOLLS (2002). O gráfico foi construído pelo pesquisador, em cartolina branca e afixado na sala de ordenha.

Avaliação da metodologia proposta

Os agricultores foram entrevistados para avaliar a efetividade da metodologia proposta. As entrevistas, gravadas em áudio e vídeo, foram realizadas durante a avaliação dos indicadores pelos agricultores, os quais revelavam a sua percepção em relação aos resultados do projeto e da metodologia em si. Três questões nortearam a entrevista:

questão 1 - A que vocês atribuem a melhora dos indicadores que variaram positivamente? Foi adotada alguma prática de manejo que vocês não faziam antes do projeto? Foi difícil realizá-las?

questão 2 - A que vocês atribuem os indicadores que se mantiveram ou variaram negativamente? Houve alguma dificuldade para adotar alguma prática de manejo?

questão 3 - Na opinião de vocês, a metodologia utilizada foi válida para avaliar as práticas de manejo da ordenha? Que sugestões vocês dariam a um técnico ou pesquisador que fosse fazer um trabalho semelhante a esse?

Ciência Rural, v.44, n.5, mai, 2014. 


\section{RESULTADOS}

Características socioeconômicas, demográficas e de rebanho das UPF estudadas

A maior parte da renda das propriedades era oriunda da atividade leiteira. Em três UPFs, as mulheres ocupavam-se da atividade leiteira e eram responsáveis pelas tarefas domésticas. Em apenas em uma delas, a mulher dedicava-se exclusivamente à atividade leiteira. Em todas as UPFs, os filhos trabalhavam na propriedade, envolvendo-se diretamente com a atividade leiteira. Todas as famílias tiveram acesso a crédito recentemente, sendo o recurso utilizado para aquisição de vacas e equipamentos de ordenha. Todas as unidades receberam assistência técnica pública, privada e/ou da Associação de Microbacias.

O tamanho médio das propriedades era de 21,5 ha, sendo 12,9 ha utilizados com pastagens para o gado leiteiro. O rebanho médio era de 16 vacas em lactação e a produção média diária, de 181 litros de leite. A base da alimentação do gado era o pasto em sistema rotativo. Os animais permaneciam o tempo todo no pasto o ano inteiro. Durante a ordenha, era fornecido complemento alimentar (ração e silagem).

As raças predominantes eram a Holandesa e a Jersey e a cruza das duas. A mastite foi relatada como a principal doença do rebanho em duas UPF que não realizavam o teste da caneca de fundo preto para diagnóstico desta. Três delas realizavam o CMT, duas com frequência quinzenal e uma com frequência mensal. Duas unidades possuíam sala de espera de terra com cobertura e, nas outras duas, os animais aguardavam no potreiro. Em três UPFs, o piso da sala de ordenha era de concreto e, em uma delas, era de madeira. A ordenha era mecanizada, no sistema lado a lado/balde ao pé em três delas e espinha de peixe em uma.

Indicadores de manejo sanitário de ordenha e uso do gráfico tipo ameba

Foram identificados 53 descritores, os quais foram agrupados em 13 indicadores, na seguinte ordem de importância: Saúde animal, Higiene de equipamentos, Alimentação Bem-estar animal, Higiene do ordenhador, Refrigeração do leite, Manutenção de equipamentos CMT, Higiene das instalações, Higiene dos animais, Satisfação na atividade, Orientação técnica e Resíduos de medicamentos.

Os gráficos do tipo ameba visavam a permitir aos agricultores comparar os resultados com os obtidos no mês anterior, através da observação da variação de cada indicador. Quanto mais "cheia” a ameba, mais perto do ideal se encontrariam as práticas de manejo sanitário de ordenha (Figura 1).

Houve uma sensível melhoria na UPF 1 na qualidade do leite, com valores de CCS 1.100.000, 857.000 e 628.000cél ml ${ }^{-1}$ e CPP de 755.000, 183.000 e 181.000cél $\mathrm{ml}^{-1}$, respectivamente, nos três meses consecutivos. A UPF 2 manteve os padrões dentro do ideal desde o início do estudo: CCS: 305.000, 181.000 e 343.000; CPP: 63.000, 42.000 e 28.000 cél/ml, ao longo dos três meses. Na UPF 3, houve melhoria na CPP, que baixou dos 2.470 .000 cél/ml no primeiro mês para 356.000 no segundo e 31.000 cél/ ml no terceiro mês; já a CSS se manteve nos padrões, com pouca variação ao longo do período (478.000, 511.000 e 393.000 cél $/ \mathrm{ml}^{-1}$ ). A UPF 4 manteve valores acima do limite máximo permitido ao longo de todo o período: CCS: 273.000, 784.000 e 688.000 cél $/ \mathrm{ml}^{-1} \mathrm{e}$ CPP: 747.000, 1.131 .000 e 2.429 .000 cél $/ \mathrm{ml}^{-1}$.

\section{Avaliação da metodologia}

A metodologia proporcionou a apropriação das práticas, como pode ser observado na fala de um agricultor da UPF 4: "controle de mastite, por exemplo, é pré-dipping (...?) às vezes a gente fazia, às vezes não fazia, então a gente começou a fazer... Avaliando bem, tudo entra na qualidade do leite, né... porque tudo faz parte... o barro, a limpeza da ordenhadeira, o resfriamento do leite, tudo faz parte da qualidade do leite. Então... quem não corre tem que sair da estrada, como se diz né...”

Essa apropriação pode ser percebida em diferentes aspectos do manejo, como, por exemplo, na "higiene de equipamentos”: “Tipo assim, desde a higienização da ordenha, a gente trabalhava com os produtos misturados, a gente separou, lava tipo o alcalino semanalmente, né, e o ácido duas vez por semana, desde higienização pessoal, roupa...” (UPF 2). “(...) é, a gente vê que... a gente mudou muito a maneira de fazer pelo que a gente estava fazendo, principalmente, na questão de higiene, foi o ponto chave que levou a qualidade do leite ser bem melhor do que a gente vinha tendo. Foi dedicado bastante em cima de limpeza, tanto da parte de mangueiras, usando água de melhor qualidade, água boa pra fazer limpeza, água quente, detergente, então uma série de fatores que a gente mudou” (UPF 3).

A metodologia foi capaz de provocar mudanças de percepção, apesar da necessidade de algumas mudanças estruturais nas propriedades, conforme se verifica nas falas a respeito dos indicadores que menos variaram: "É a parte financeira... se tivesse dinheiro fazia ali um estábulo e, como tem nas perguntas, já saía de perto da esterqueira, já não entra 


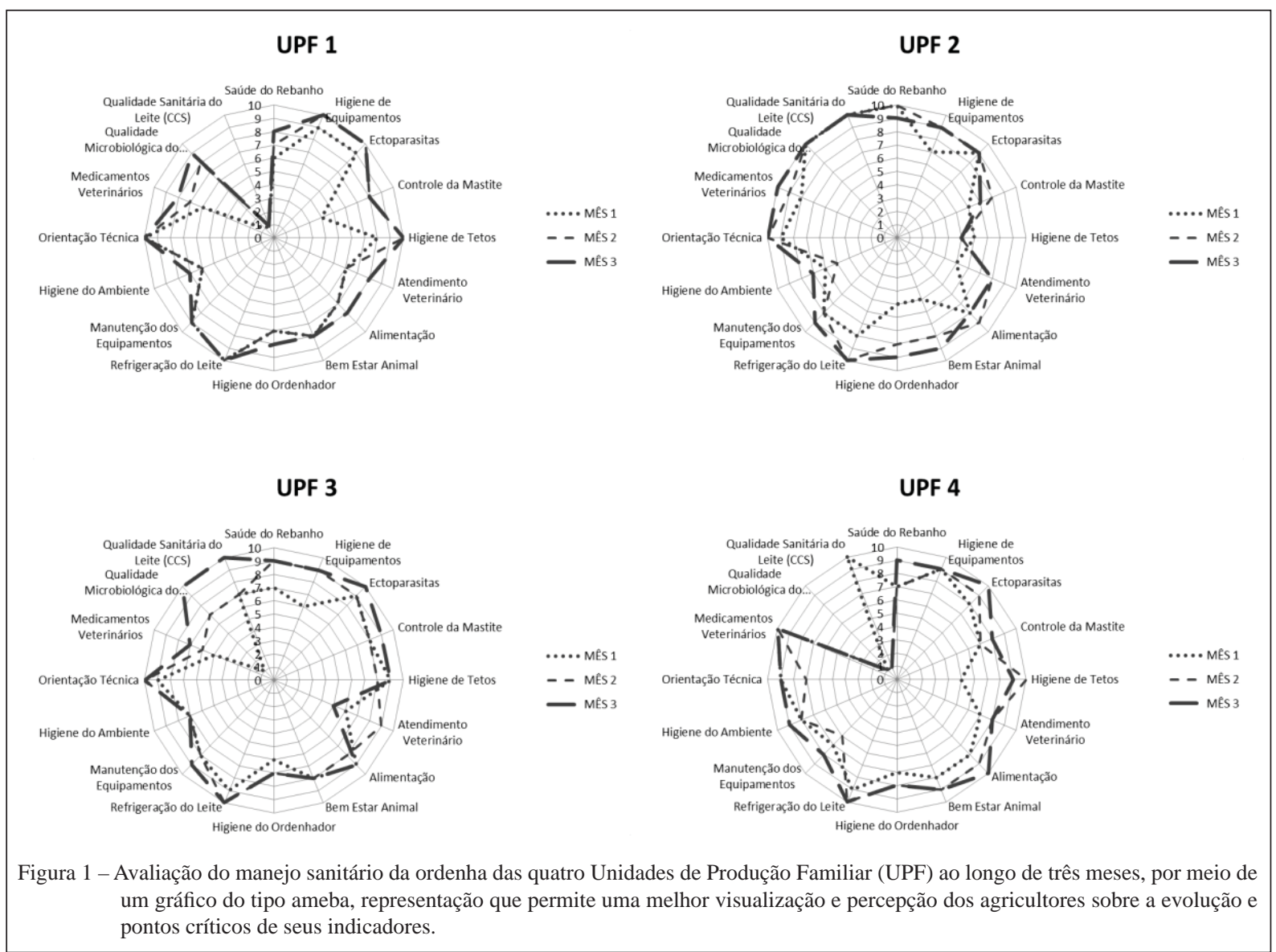

mais animais, já pega mais o sol, já influencia no bemestar animal, porque tu já vai ter a sala certinha, né? Pra vacinar, tudo, né? Eu acho que é isso” (UPF 1).“Pra gente mudar isso teria que construir um estábulo novo, daria pra mudar, mas pouco... Desde a ventilação, a luz do sol, a gente tá tentando ver, pra mudar de lugar, construir outro estábulo diferente” (UPF 2).“Aqui a higiene do ambiente a gente não pode chegar no máximo, no caso, que nem agora, porque as instalações não são bem adequadas pra seguir as normas bem certinho. A gente lava a estrebaria com água, mas o ambiente já é um pouquinho fora do padrão como deveria ser, então são uns pontos que a gente vai tentar de corrigir mais adiante” (UPF 3).

Essas declarações dos agricultores demonstram que os principais objetivos, quanto às mudanças de percepção e de atitude sobre as práticas do manejo da ordenha, foram alcançados. Os próprios agricultores destacaram que o mérito da metodologia está associado ao fato de ela proporcionar o questionamento da realidade imediata pelas famílias:

"Eu acho que sim, porque, quando vem outro técnico num curso, eles ensinam que tem que fazer assim, assim, assim, e aqui a gente que deu as sugestões. Não foi tu que veio aqui e disse que tinha que ser assim, nós que percebemos o que estava errado e o que tinha que mudar na verdade. Isso aí foi bom, bem importante” (UPF 1).

"O que mais chamou atenção foi que a nossa família viu que tem que partir para um outro lado, o lado da realidade, tem que se dedicar nessa metodologia pra conseguir um resultado bom. ... Se você não praticar em casa não adianta né, tem que fazer as coisas dentro de como é pra ser feito, daí a gente tem um resultado bom” (UPF 3).

\section{DISCUSSÃO}

Considerando os cenários brasileiro e catarinense, em que as intervenções extensionistas tradicionais não têm sido efetivas para promover a adoção de práticas de manejo sanitário da ordenha, a proposta metodológica apresentada neste estudo mostrou-se válida e coerente com as novas diretrizes apontadas para as ações de ATER, em função de seu caráter participativo e educativo. O fato de o 
pesquisador realizar, junto com os agricultores, o teste CMT caracterizou o trabalho, desde o início, como um trabalho problematizador: a prática o fazia refletir sobre a atitude que deveria tomar em relação ao manejo sanitário. Assim, assemelhou-se ao proposto por ULLER-GÓMEZ \& GARTNER (2008), que explicam que, na discussão iniciada com base na realidade dos agricultores, a postura do educador deve ser a de desafiar os agricultores a enxergarem a situação de outro ângulo, o que é chamado de "problematização". Essa postura dialógica assumida pelo educador cria as condições necessárias para a apreensão do conhecimento por parte do agricultor e um comprometimento entre ambos (FREIRE, 1985).

$\mathrm{O}$ processo de capacitação remeteu à questões significativas dos agricultores, "situaçõeslimite" que deveriam ser superadas para que eles pudessem avançar qualitativamente no manejo sanitário da ordenha, e cuja superação exigia um conhecimento novo. FREIRE (1987) explica que, para alcançar a humanização, é imprescindível a superação das "situações-limite”, somente alcançada pelo fazer mais crítico na sua ação, ligada à "percepção do conhecimento novo ou inédito viável”.

Durante a construção dos indicadores, percebeu-se que os agricultores já tinham um bom conhecimento sobre o tema e a dinâmica utilizada na oficina foi sensível para identificar esses conhecimentos. De modo geral, na avaliação do indicador "controle da mastite", verificou-se que o diagnóstico (CMT e caneca de fundo preto) não era realizado ou a frequência não era adequada. A partir da capacitação e da realização dessa prática com o pesquisador, os produtores perceberam a sua importância e passaram a adotá-la. VALLIN et al. (2009) identificaram que práticas simples, como o desprezo dos três primeiros jatos de leite, lavagem correta dos utensílios de ordenha, pré-dipping e eliminação da água residual dos utensílios de ordenha são suficientes para a melhoria da qualidade do leite. A higiene de equipamentos, um indicador apontado pelos agricultores como o segundo mais importante, foi o que mais variou positivamente após a intervenção. Ao fim do projeto, essa foi a prática mais adotada em todas as UPF, juntamente com a refrigeração do leite.

A avaliação e monitoração mensal, pelos próprios agricultores, dos indicadores selecionados e representados em um gráfico permitiu-lhes que se sentissem sujeitos do processo. Em decorrência disso, passaram a ter mais responsabilidade com seu próprio ato de "fazer as coisas", relacionando a sua intervenção prática principalmente aos dois indicadores qualitativos, a CCS e a CPP. A sensível redução de CPP em três das quatro propriedades está relacionada à adoção das melhores práticas de higiene de equipamentos e de refrigeração do leite, relatadas pelos agricultores. Já a CCS, por estar mais relacionada a mastites em geral (agudas e crônicas), pode demandar um tempo maior para a percepção de melhorias.

As notas atribuídas aos indicadores estruturais foram as que menos variaram. A sua baixa adoção se justifica pelo fato de as intervenções práticas, relacionadas aos parâmetros estabelecidos, implicavam adequação do espaço físico da sala de ordenha, um processo que demanda tempo e capital. A infraestrutura, a falta de equipamento ou o desenho inadequado da sala de ordenha reconhecidamente afetam a implantação de um programa de boas práticas no manejo de ordenha (TAVOLARO, 2004).

Os depoimentos obtidos nas entrevistas indicam que os agricultores internalizaram os aspectos mais importantes relacionados a cada indicador, o que permite atribuir méritos à metodologia como ferramenta de autoavaliação. FREIRE (1967) afirma que, "no processo de aprendizagem, só aprende verdadeiramente aquele que se apropria do aprendido, transforma-o em apreendido, reinventando-o, aplicando o aprendidoapreendido a situações reais concretas”.

A escolha dos gráficos do tipo "ameba” para representação visual dos indicadores merece destaque para o sucesso da ferramenta metodológica, pois mostrou-se um método simples e eficiente. Durante as entrevistas finais, os agricultores se expressavam e apontavam frequentemente para o gráfico, ao justificar os "porquês” da maior ou menor variação dos indicadores, demonstrando assimilar o objetivo de seu uso. ALTIERI \& NICHOLLS (2002) reforçam que a "ameba", além de permitir aos agricultores visualizarem suas práticas pela representação visual de seus indicadores, permite observar quais aspectos estão mais debilitados e precisam ser priorizados. Pese-se ainda o fato de que o gráfico afixado na sala de ordenha reforçava, através da imagem, a responsabilidade do agricultor com relação às suas práticas.

Os relatos dos agricultores sobre a proposta metodológica demonstram a superioridade de uma metodologia participativa de caráter humanista em relação às propostas difusionistas. TAVOLARO (2004) afirma que "uma das razões para o programa de Boas Práticas de Fabricação não ser amplamente aceito pode ser o fato de a proposta vir de fora, da universidade para os proprietários rurais, e estes, em princípio, enxergarem como algo que não pediram, não havendo comprometimento suficiente”. Outra 
conclusão da autora foi que "as modificações sugeridas não foram adotadas, provavelmente, por que não se conseguiu uma participação ativa dos proprietários e funcionários na elaboração dos objetivos”. Portanto, o diferencial da presente proposta dentro da discussão da pedagogia de ATER também foi identificado na fala de um agricultor, que, na entrevista final, referiu-se à importância de "praticar o aprendido". No entanto, a consolidação da metodologia MESMIS para a avaliação de sistemas de produção animal requer um maior número de experiências, de tempo mais longo e com o envolvimento de um número maior de agricultores.

\section{CONCLUSÃO}

A metodologia foi eficaz para promover, em curto prazo, mudanças de percepção e comportamentos nos agricultores, uma vez que houve melhoria de vários indicadores, conforme a avaliação dos agricultores e confirmado pelos testes laboratoriais. A proposta metodológica participativa utilizada neste trabalho, dentro de uma perspectiva emancipadora, mostrou-se coerente com as premissas da Política Nacional de Assistência Técnica e Extensão Rural - PNATER. Além disso, cumpriu com os objetivos propostos de busca de uma ferramenta de intervenção extensionista, capaz de promover a autonomia e a emancipação dos agricultores da dependência tecnicista e desumanizadora a que estiveram submetidos durante muitos anos.

\section{REFERÊNCIAS}

ALTIERI, M.A.; NICHOLLS, C.I. Un método agroecológico rápido para la evaluación de la sostenibilidad de cafetales. Manejo Integrado de Plagas y Agroecología, Costa Rica, n.64, p.17-24, 2002.

ASTIER, M. et al. Assessing the sustainability of small farmer natural resource management systems. A critical analysis of the MESMIS program (1995-2010). Ecology and Society, v.17, n.3, p.25, 2012. Disponível em: <http://www.ecologyandsociety.org/ vol17/iss3/art25/>. Acesso em: 10 de out. 2013. doi10.5751/ES04910-170325.

BRASIL. Ministério da Agricultura, Pecuária e Abastecimento. Normativa n.62 de 29 de dezembro de 2011. Diário Oficial da União, Brasília, DF, Brasil, 2011.
BRASIL. Ministério do Desenvolvimento Agrário. Secretária da Agricultura Familiar. Política Nacional de Assistência Técnica e Extensão Rural. Brasília, DF, Brasil, 2004.

CARRILLO, A.T. Generating knowledge in popular education: from participatory research to the systematization of experience. International Journal of Action Research, v.6, n.2-3, p.196-222, 2010.

CASADO, G.I.G.; MIELGO, A.M.A. La investigación participativa en agroecología: una herramienta para el desarrollo sustentable. Ecosistemas, v.16, p.24-36, 2007.

COSTA, J.H.C. et al. A survey of management practices that influence production and welfare of dairy cattle on family farms in southern Brazil. Journal of Dairy Science, v.96, p.307-317, 2013.

ENRÍQUEZ, D. et al. Avaliação da adoção de práticas de manejo do rebanho leiteiro no processo de transição para a criação animal agroecológica. Revista Brasileira de Agroecologia, v.2, p.120123, 2007.

FREIRE, P. Educação como prática da liberdade. RJ: Paz e Terra, 1967. 157p.

FREIRE, P. Extensão ou comunicação? 8.ed. Rio de Janeiro: Paz e Terra, 1985. 93p.

FREIRE, P. Pedagogia do oprimido. 17 ed. Rio de Janeiro: Paz e Terra, 1987. 184p.

MUSSOI, E.M. Curso de especialização em extensão rural para o desenvolvimento sustentável: uma experiência inovadora e transformadora. In: LIMA, J.R.T.; FIGUEIREDO, M.A.B. (Orgs.). Extensão rural, desafios de novos tempos: agroecologia e sustentabilidade. Recife: Bagaço, 2006. 171p, p.159-171.

TAVOLARO, P. Desenvolvimento de habilidades e técnicas de manejo sanitário aplicadas a ordenhadores de leite de cabra através de projeto educativo participativo. 2004. 131f. Tese (Doutorado em Medicina Veterinária) - Universidade de São Paulo, SP.

TAVOLARO, P. et al. Avaliação do conhecimento em práticas de higiene: uma abordagem qualitativa. Interface - Comunicação, Saúde, Educação, v.9, p.243-254, 2006.

ULLER-GÓMEZ, C.; GARTNER, C. Um caminho para conhecer e transformar nossa comunidade. Florianópolis: EPAGRI/MB2, 2008. 111p.

VALLIN, V.M. et al. Melhoria da qualidade do leite a partir da implantação de boas práticas de higiene na ordenha em 19 municípios da região central do Paraná. Ciências Agrárias, Londrina, v.30, p.181-188, 2009. 